\title{
Numerical modeling in arterial hemodynamics incorporating fluid- structure interaction and microcirculation
}

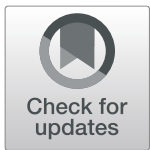

Fan $\mathrm{He}^{1^{*}}$, Lu Hua ${ }^{2^{*}}$ and Tingting Guo ${ }^{2}$

\begin{abstract}
Background: The effects of arterial wall compliance on blood flow have been revealed using fluid-structure interaction in last decades. However, microcirculation is not considered in previous researches. In fact, microcirculation plays a key role in regulating blood flow. Therefore, it is very necessary to involve microcirculation in arterial hemodynamics.
\end{abstract}

Objective: The main purpose of the present study is to investigate how wall compliance affects the flow characteristics and to establish the comparisons of these flow variables with rigid wall when microcirculation is considered.

Methods: We present numerical modeling in arterial hemodynamics incorporating fluid-structure interaction and microcirculation. A novel outlet boundary condition is employed to prescribe microcirculation in an idealised model.

Results: The novel finding in this work is that wall compliance under the consideration of microcirculation leads to the increase of wall shear stress in contrast to rigid wall, contrary to the traditional result that wall compliance makes wall shear stress decrease when a constant or time dependent pressure is specified at an outlet.

Conclusions: This work provides the valuable study of hemodynamics under physiological and realistic boundary conditions and proves that wall compliance may have a positive impact on wall shear stress based on this model. This methodology in this paper could be used in real model simulations.

Keywords: Fluid-structure interaction, Microcirculation, Hemodynamics, Outlet boundary condition, Numerical modeling

\footnotetext{
* Correspondence: hefan@bucea.edu.cn; ethannan@126.com

'Department of Mechanics, School of Science, Beijing University of Civil Engineering and Architecture, Beijing 100044, China

${ }^{2}$ Thrombosis Center, National Clinical Research Center for Cardiovascular Diseases, State Key Laboratory of Cardiovascular Disease, Fuwai Hospital, National Center for Cardiovascular Diseases, Chinese Academy of Medical Sciences and Peking Union Medical College, Beijing 100037, China
}

(c) The Author(s). 2021 Open Access This article is licensed under a Creative Commons Attribution 4.0 International License, which permits use, sharing, adaptation, distribution and reproduction in any medium or format, as long as you give appropriate credit to the original author(s) and the source, provide a link to the Creative Commons licence, and indicate if changes were made. The images or other third party material in this article are included in the article's Creative Commons licence, unless indicated otherwise in a credit line to the material. If material is not included in the article's Creative Commons licence and your intended use is not permitted by statutory regulation or exceeds the permitted use, you will need to obtain permission directly from the copyright holder. To view a copy of this licence, visit http://creativecommons.org/licenses/by/4.0/ The Creative Commons Public Domain Dedication waiver (http://creativecommons.org/publicdomain/zero/1.0/) applies to the data made available in this article, unless otherwise stated in a credit line to the data. 


\section{Introduction}

As an important portion of circulatory system, microcirculation plays a key role and it should not be ignored. It serves to regulate blood flow and tissue perfusion thereby affecting blood pressure and responses to inflammation. Microcirculation presents the greatest resistance to blood flow so that the pressure wave propagation is impeded and then the reflection is produced. Thus, the fluctuation range of blood pressures gradually largens and that of flow velocity lessens from the aorta to peripheral arteries. Therefore, the pressure proximal to microcirculation is higher and the velocity is lower than those distal to microcirculation. These microvessels in microcirculation complete the change of pulsatile to steady flow by repelling the pulsations that enter from the larger arteries. It has been indicated that the cardiovascular disease risk depends on the presence and the severity of microcirculation dysfunction $[1,2]$. As an important prognostic factor, microcirculation function plays a role in regulating blood flow to distal organs [3]. Without question, a single outlet boundary condition is not appropriate. However, a specific pressure or velocity profile at an outlet is often given by a traditional approach in hemodynamic simulations. Therefore, the traditional approach could not well reflect the resistance provided by microcirculation. Fortunately, we could deal with microcirculation using a porous model, which can capture the essential seepage features in microcirculation. It has been proved that a porous model could be used to exactly simulate the flow in microcirculation [4-6]. Microcirculatory effects could be addressed as outlet boundary conditions in hemodynamic simulations by a porous model, which is the likely best approach. Therefore, the function of the distal microcirculation may be represented by a seepage condition at an outlet, which can be found in our previous study incorporating microcirculation [7].

In addition, as well known, the arterial wall is compliant. The mechanical loading is contributed and a blood vessel is progressively expanded by arterial compliance [8]. Consequently, we consider arterial compliance and perform the fluid-structure interaction between blood and arterial wall. It is available for incorporating such effects that fluid-structure interaction is applied to the cardiovascular system [9]. Due to the importance of arterial compliance on flow patterns, it is significant that fluidstructure interaction in hemodynamic simulations has been pursued [10-12]. Researchers have focused on the role of arterial compliance using fluid-structure interaction and deduced that wall shear stresses are decreased by compliant wall in comparison with rigid wall [13-15]. As noted, simple boundary conditions have been employed in most previous hemodynamics modeling, such as the specification of a constant or time dependent pressure, and no perivascular support. However, physiological and realistic boundary conditions are necessary for clinical interest.

Microcirculation adjusts flow resistance, which is relevant for hemodynamic simulations. The deformation of compliant wall affects flow patterns. Given the importance of microcirculation and wall compliance on the character of the blood flow, it is remarkable that most research in vascular biomechanics has been pursued separately. The combination of arterial wall compliance and microcirculation effects on blood flow are still absent.

Arterial diseases can benefit from a numerical approach combined with fluid-structure interaction and microcirculation to determine flow alterations. In this work, numerical modeling in arterial hemodynamics is presented incorporating fluid-structure interaction and microcirculation. This manuscript aims to investigate on the effects of arterial compliance on the flow characteristics and to compare these flow variables with rigid wall when microcirculation is considered.

\section{The model and methodology}

Numerical modeling in arterial hemodynamics incorporating fluid-structure interaction and microcirculation is performed through constructing a standard framework in Fig. 1. The geometry is plotted to elaborate the application of a seepage condition at an outlet. In Fig. 1, D represents the diameter and equals $20 \mathrm{~mm}$. The computational domains contain artery and microcirculation zones. The locations of interest sections are denoted by S1, S2, S3 and S4. Due to the arterial compliance, fluidstructure interaction is considered and the wall thickness is set to $2 \mathrm{~mm}$ in artery zone. However, in microcirculation zone, the rigid wall is assumed because of the tiny deformation of the vessel in microcirculation.

The Navier-Stokes equations with arbitrary Lagrangian-Eulerian formulation are used as the governing equations in the frame of artery zone [16].

$$
\begin{aligned}
& \rho\left(\frac{\partial \mathbf{u}}{\partial t}+\left(\left(\mathbf{u}-\mathbf{u}_{m}\right) \cdot \nabla\right) \mathbf{u}\right)=-\nabla p+\nabla \cdot \mathbf{T} \\
& \nabla \cdot \mathbf{u}=0
\end{aligned}
$$

Where $\mathbf{u}$ is the fluid velocity vector, $\mathbf{u}_{m}$ is the mesh velocity, $p$ is the fluid pressure, $\rho$ is the fluid density and set to $1050 \mathrm{~kg} / \mathrm{m}^{3}$.

$$
\begin{aligned}
& \mathbf{T}=2 \eta(\dot{\gamma}) \mathbf{D} \\
& \mathbf{D}=\frac{1}{2}\left(\nabla \mathbf{u}+\nabla \mathbf{u}^{\mathbf{T}}\right)
\end{aligned}
$$

Where $\eta$ and $\dot{\gamma}$ are the blood viscosity and the shear rate respectively. $\eta$ is dependent of $\dot{\gamma}$ for a nonNewtonian fluid. 


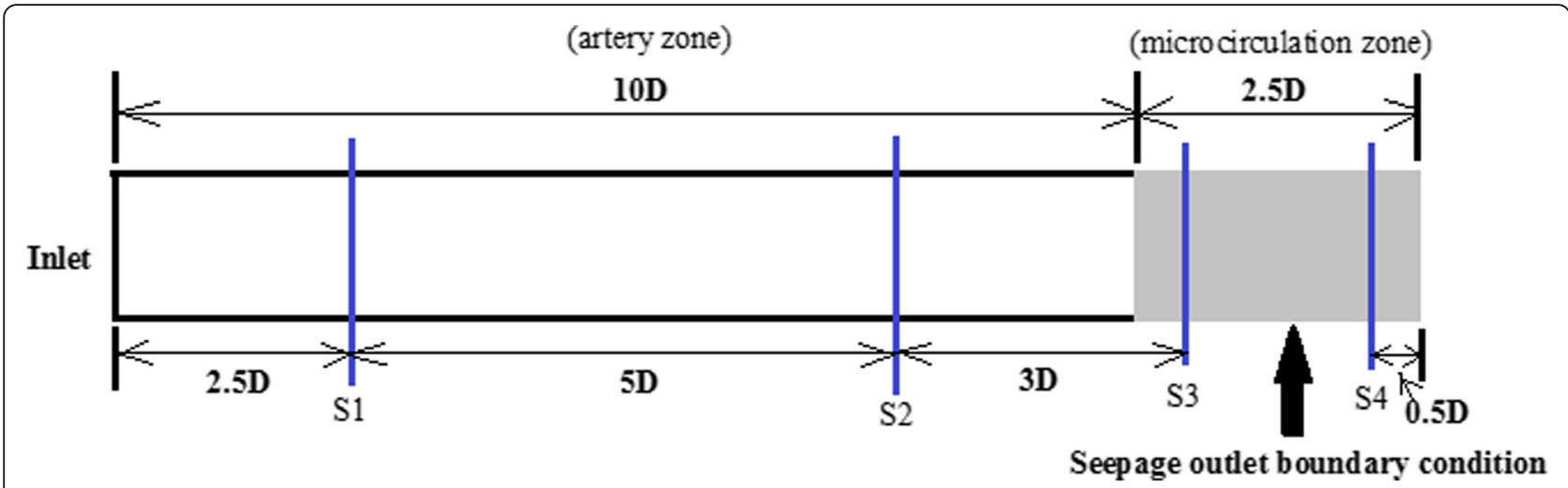

Fig. 1 The application of a seepage condition at an outlet

Since blood demonstrates non-Newtonian behavior, we employ the Carreau-Yasuda model in this work [17].

$$
\frac{\eta-\eta_{\infty}}{\eta_{0}-\eta_{\infty}}=\left[1+(\lambda \dot{\gamma})^{a}\right]^{(n-1) / a}
$$

Where $\eta_{\infty}=2.2 \times 10^{-3} \mathrm{~Pa} \cdot \mathrm{s}, \quad \eta_{0}=22 \times 10^{-3}$ Pa.s, $\lambda=$ $0.110 \mathrm{~s}, a=0.644, n=0.392$ [18].

In this simulation, a porous model is adopted to deal with microcirculation. The permeability can be computed by the following empirical equation.

$$
k=\frac{d^{2} \phi^{3}}{180(1-\phi)^{2}}
$$

Where $\phi$ represents the porosity and is set to 0.5 [19]. $d$ denotes microvessel's diameter in the microcirculation and equals $8 \mu m$ [20].

To simplify the simulation, we make hypotheses that the arterial wall is an isotropic, incompressible and linear-elastic material. Thus, the governing equations are as follows [21].

$$
\begin{aligned}
& \rho_{w} \frac{\partial^{2} d_{i}}{\partial t^{2}}=\frac{\partial \sigma_{i j}}{\partial x_{j}}+F_{i} \\
& \varepsilon_{i j}=\frac{1+v}{E} \sigma_{i j}-\frac{v}{E} \sigma_{k k} \delta_{i j}
\end{aligned}
$$

Where $\sigma_{i j}, \varepsilon_{i j}, d_{i}$ and $F_{i}$ are the components of the stress tensor, strain tensor, displacements and the body force acting on the solid.

In this simulation, we set the density of arterial wall $\rho_{w}$ $=1120 \mathrm{~kg} / \mathrm{m}^{3}$, Young's modulus $E=5 \mathrm{MPa}$ [22] and Poisson ratio $v=0.499[23]$.

The governing equations in the frame of microcirculation zone are as follows.

$$
\begin{aligned}
\rho\left(\frac{\partial(\phi \mathbf{u})}{\partial t}+\mathbf{u} \cdot \nabla(\phi \mathbf{u})\right)= & -\nabla(\phi p)+\nabla \\
& \cdot(\phi \mathbf{T})-\frac{\phi^{2} \eta}{k} \mathbf{u} \\
\nabla \cdot(\phi \mathbf{u})=0 &
\end{aligned}
$$

Figure 2 plots the velocity waveform, which is imposed at the inlet and the period is $0.8 \mathrm{~s}$ [22]. Subsequently, we specify the seepage microcirculation condition at the outlet. The conservative interface flux is required when blood runs from artery to microcirculation zones. Boundary conditions at the artery-microcirculation interface are given to guarantee the continuity of mass and pressure and the conservation of mass and momentum across the interface. We solve the governing equations plus associated boundary conditions for the fluidstructure interaction numerical modeling.

Both vessel ends are constrained to be entirely fixed. On the fluid-structure interface, there are the assumptions that the motions of fluid and wall are identical and there is no slipping [24].

$$
\left.(u, v, w)\right|_{\Omega}=\frac{\partial X}{\partial t}
$$

Where $\Omega$ denotes the wall, $X=(r, \theta, z)$ are the radial, circumferential and axial position components of the deformed wall.

Two sets of commercial codes are employed to solve the fluid-structure interaction. We use ANSYS to deal with the structural problem, while the transient behavior of the fluid domain is solved by CFX. A high-resolution advection scheme is used to spatially discretize the equations. The second-order backward difference is adopted. The equations can be solved by the arbitrary Lagrangian-Eulerian algorithm, which sequentially computes fluid, structural and remeshing problems using a staggered approach. Fluid forces, solid displacements and velocities are transferred and 


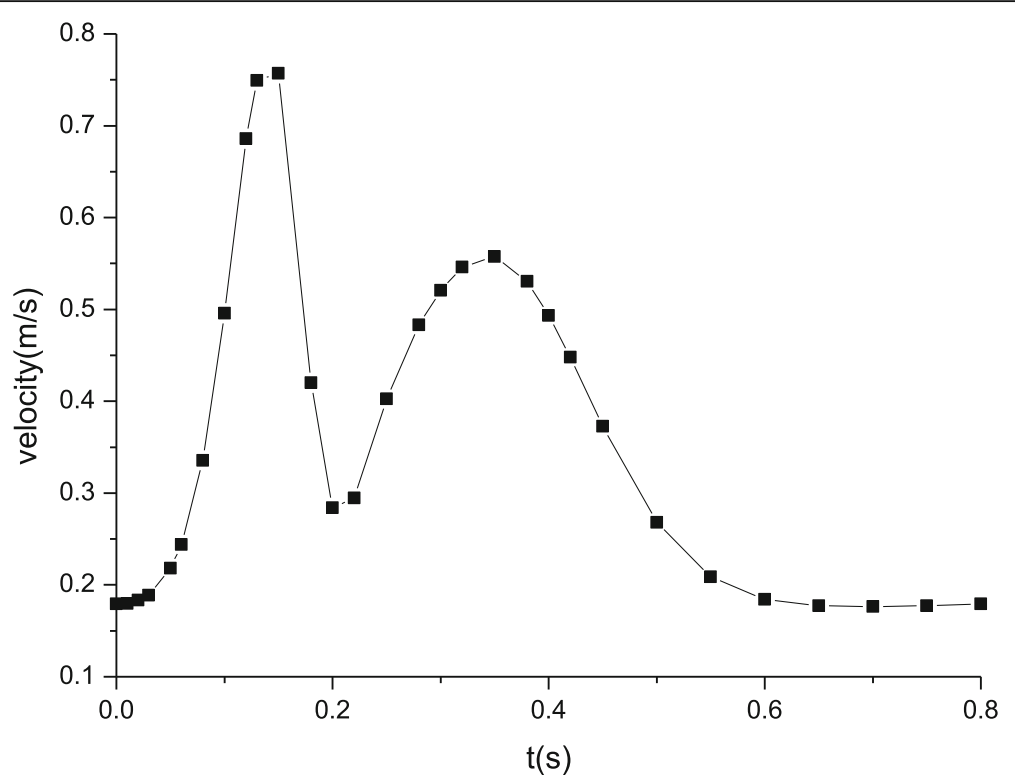

Fig. 2 The velocity at the inlet

exchanged across the fluid-structure interface through the coupling of the two sets of codes. Each time step is set to $4 \times 10^{-3} \mathrm{~s}$. The variable residuals are less than $10^{-4}$ and govern the number of iterations. Mesh dependency test is conducted to assure the mesh quality and simulation accuracy. We calculate the results until they become independent from the mesh. The numerical and accurate results are obtained using the proper mesh $(104,400$ four-node fluid elements and 13,500 eight-node solid elements). Solutions are carried out for three cardiac cycles to attain the periodic steady state. The third cycle is extracted and used for the proceeding analysis.

\section{Results}

\section{Maximum pressure distributions}

The blood pressure distributions at four characteristic sections (S1, S2, S3, S4 in Fig. 1) in a cardiac cycle are depicted in Figs. 3 and 4. The comparison of the pressures at sections $\mathrm{S} 1$ and $\mathrm{S} 2$ in Fig. 3 indicates

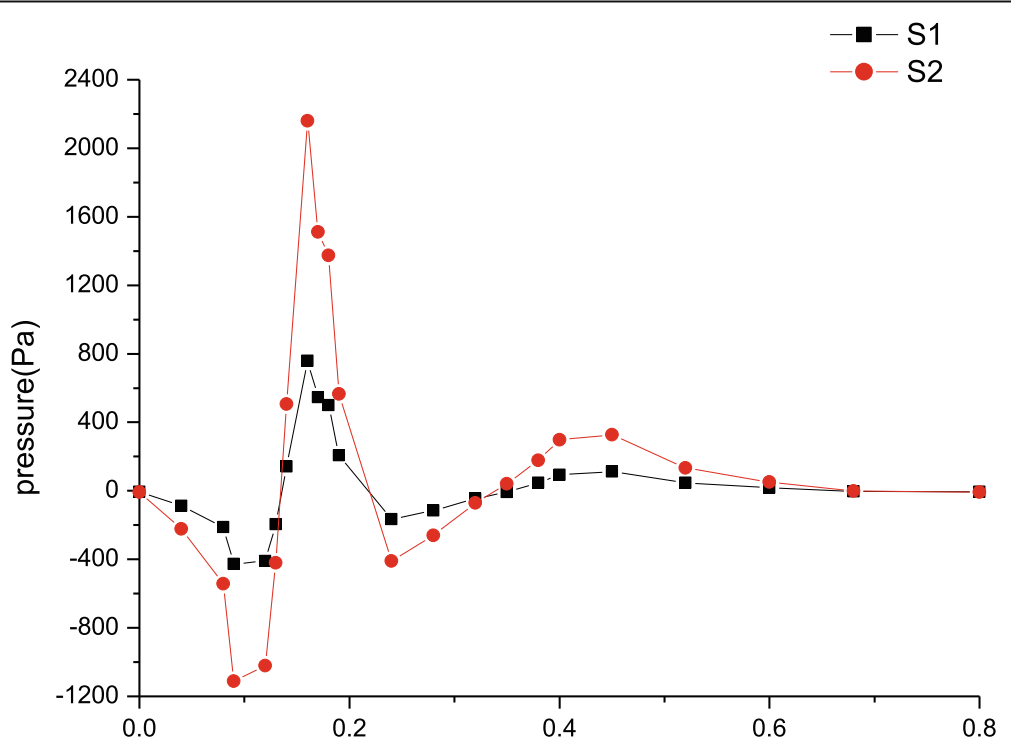

$\mathrm{t}(\mathrm{s})$

Fig. 3 The maximum pressure distributions in artery zone 


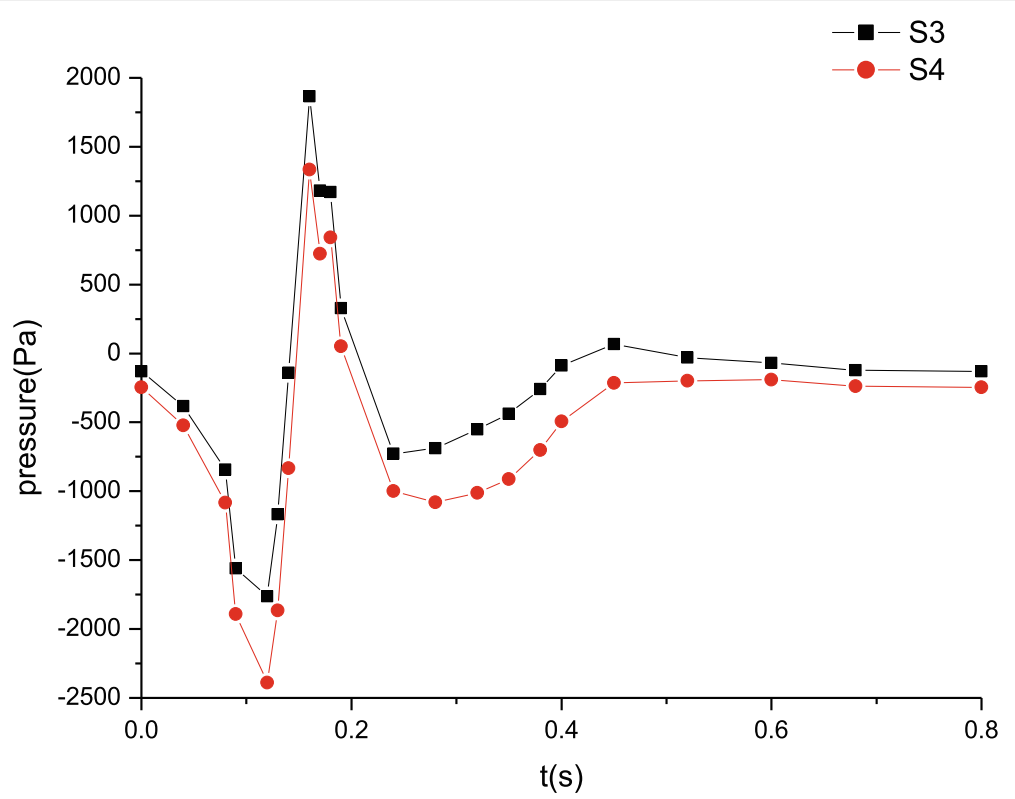

Fig. 4 The maximum pressure distributions in microcirculation zone

that the peak pressure increases and the bottom pressure decreases when the distance away from the inlet is increased. Thus, it is shown that the pressure amplitude progressively rises in artery zone. However at sections S3 and S4 of microcirculation zone, the pressure distributions are shown in Fig. 4. The pressures decrease gradually along microcirculation zone in Fig. 4. Clearly, it may be considered that the pressure amplitude almost maintains constant in microcirculation zone.

\section{Maximum velocity distributions}

The maximum velocity distributions in artery zone are plotted in Fig. 5. The inlet velocity profile determines the distributions of the time dependent velocity. In artery zone, the velocity at section $\mathrm{S} 2$ is lower than that at section S1. Away from the inlet, the increasing distance induces the velocity changes. The farther away the distance, the lower the velocity. Figure 6 shows the maximum velocity distributions in microcirculation zone, which resemble those in artery

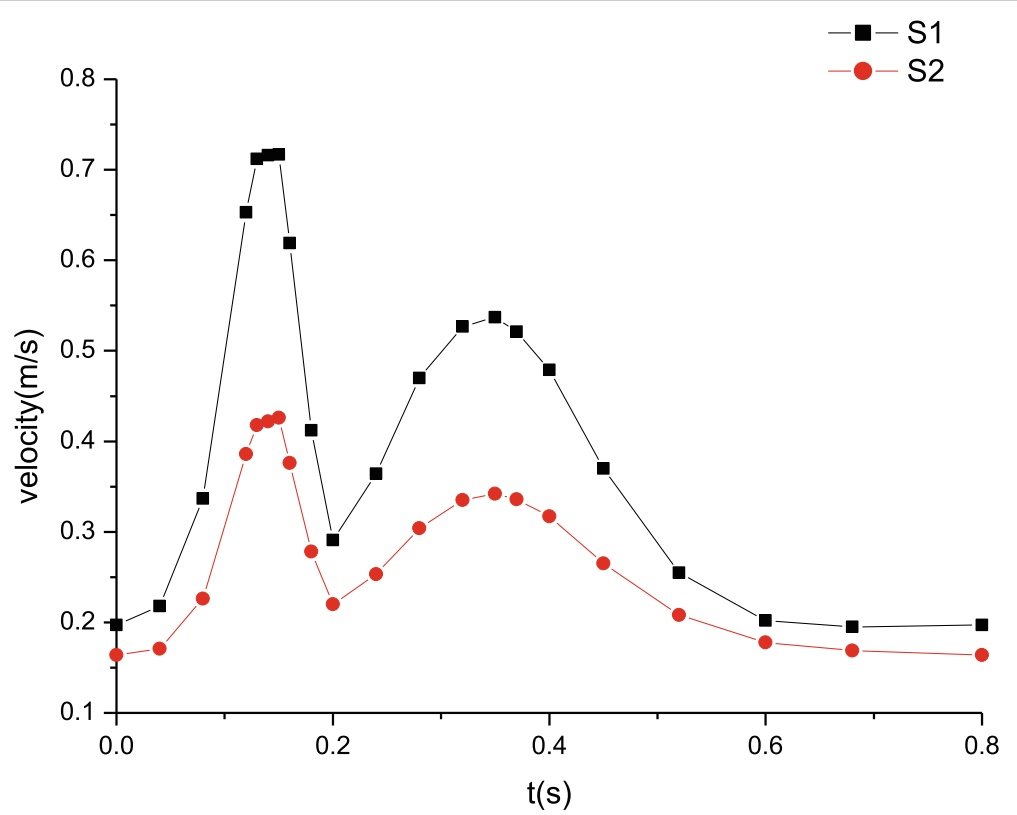

Fig. 5 The maximum velocity distributions in artery zone 


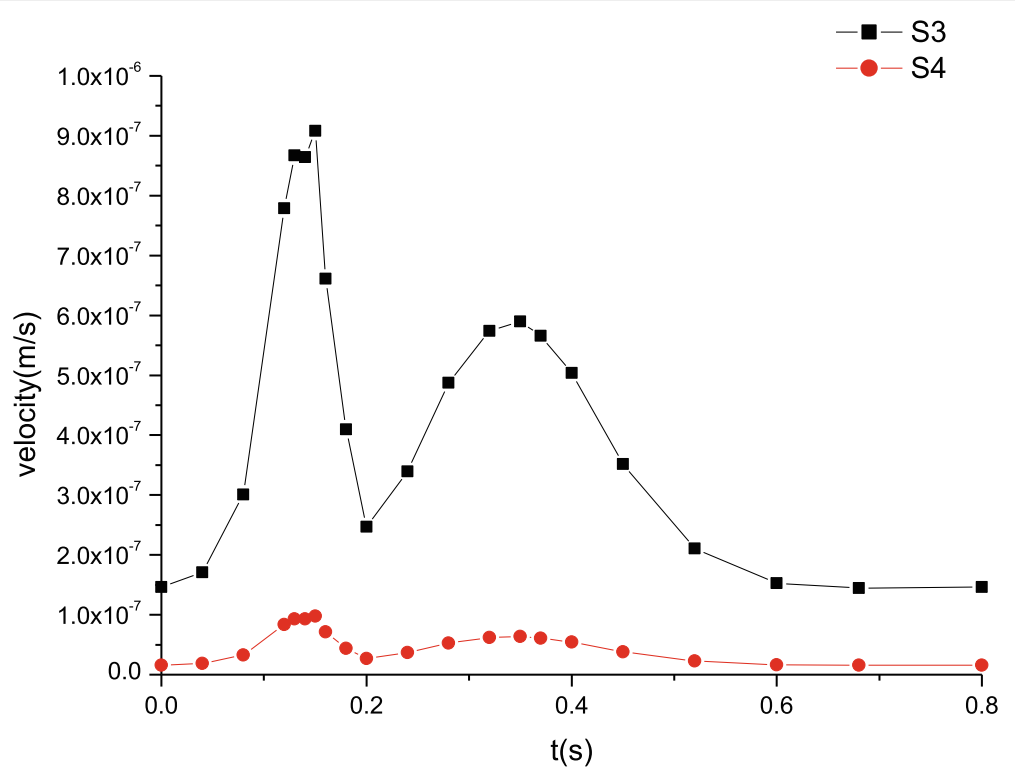

Fig. 6 The maximum velocity distributions in microcirculation zone

zone. The peak of velocity at section $\mathrm{S} 1$ attains to about $0.75 \mathrm{~m} / \mathrm{s}$ while that at section $\mathrm{S} 2$ is nearly 0.45 $\mathrm{m} / \mathrm{s}$. However, the velocity in microcirculation zone is quite lower. As well known, the blood velocity in microcirculation is extremely low due to the micron scale of the microvessel's diameter. It is seen from Fig. 6 that the velocity amplitude is also very tiny. Thus, it is often considered that there is the steady velocity in microcirculation.

\section{Maximum wall shear stress distributions}

The maximum wall shear stress distributions are shown in Figs. 7 and 8. The wall shear stress distributions remain unchanged and the trends of their variation stay the same as those of the velocity in Figs. 5 and 6. Far from the inlet, the wall shear stress gradually decreases. The peak of wall shear stress at section S1 attains to $2.1 \mathrm{~Pa}$ while that at section $\mathrm{S} 2$ is nearly 1.0 Pa. Similarly, the wall shear stress is also

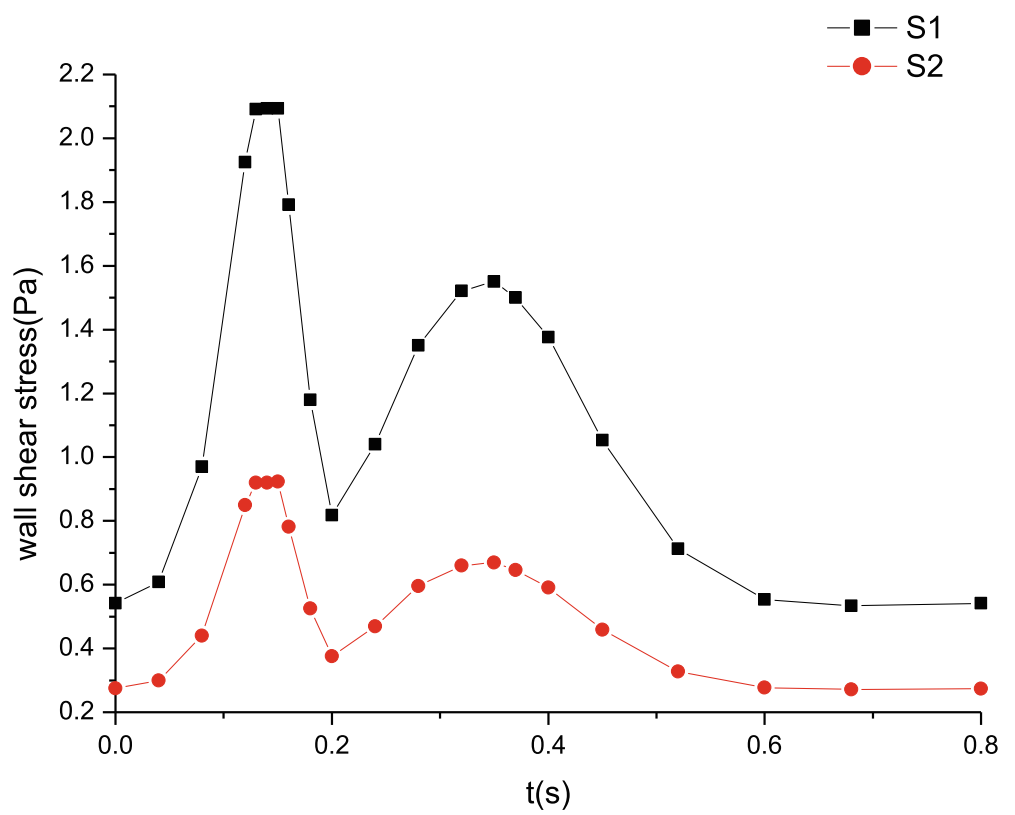

Fig. 7 The maximum wall shear stress distributions in artery zone 


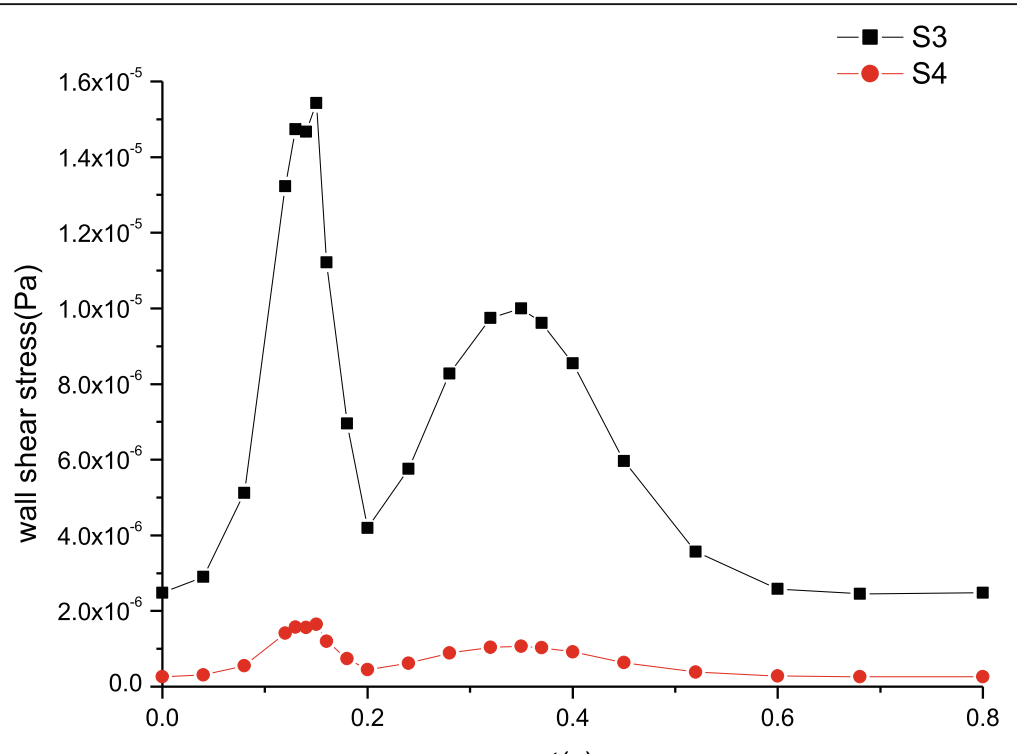

$\mathrm{t}(\mathrm{s})$

Fig. 8 The maximum wall shear stress distributions in microcirculation zone

deemed a constant value because the wall shear stress amplitude is tiny in Fig. 8.

We perform a sensitivity analysis to evaluate the effect of wall compliance on wall shear stress by changing Young's modulus. The peaks of wall shear stresses at sections S1 and S2 with Young's moduli of $4 \mathrm{MPa}, 2.5$ $\mathrm{MPa}$ and $1 \mathrm{MPa}$ are respectively $2.2 \mathrm{~Pa}, 2.4 \mathrm{~Pa}$ and $2.7 \mathrm{~Pa}$ at section $\mathrm{S} 1$ while $1.05 \mathrm{~Pa}, 1.2 \mathrm{~Pa}$ and $1.4 \mathrm{~Pa}$ at section S2.

\section{Discussion}

These simulated results are validated by comparing the estimated flow distributions in artery zone with Pedley's work, which agree well with each other [22]. The results suggest that there are differences between compliant and rigid walls. The detailed results of rigid wall can be found in our previous work when a seepage condition at an outlet is considered [7]. First, the pressure amplitude under compliant wall varies more greatly than that under rigid wall. Second, the maximum pressure under compliant wall is $2200 \mathrm{~Pa}$ or so in Fig. 3, however that under rigid wall is only approximatively $1200 \mathrm{~Pa}$ in Fig. 9. Third, the peaks of velocity and wall shear stress under compliant wall are higher than those under rigid wall, which can be seen according to the comparisons of Figs. 5, 7, 10 and 11 .

The most novel finding of this work is that the combination of compliant wall and seepage condition markedly enhances wall shear stress in comparison with the combination of rigid wall and seepage condition. Namely, in seepage-outlet-based hemodynamics modeling, wall shear stress can be increased by wall compliance. This result is quite different from those results obtained by a traditional approach that a constant or time dependent pressure is specified using fluidstructure interaction. The results based on the traditional approach indicate that wall shear stress can be decreased by wall compliance, which can be found in many researches [25-27]. However, it has become widely accepted that low wall shear stress contributes to atherogenesis $[28,29]$. A low level of wall shear stress connects with aneurysm rupture. As an important and underlying factor, it may degenerate endothelial cells and make the aneurismal wall fragility [30,31]. Hence, it seems that wall compliance does not have a positive impact on wall shear stress according to the traditional approach. Therefore, there will be contradiction if the traditional approach is employed in hemodynamics modeling. Fortunately, it is found that the contradiction can be solved if seepage-outlet-based hemodynamics modeling is used. This work shows that wall compliance actually makes wall shear stress increase, provided that microcirculation is prescribed at an outlet as a seepage condition. High wall shear stress can effectively avoid atherogenesis. Furthermore, it also explains that microcirculation plays an important role in regulating wall shear stress. The contribution of this finding indicates that wall compliance is advantageous to maintain health. As well known, the function of tissues is related to the result of the life optimization. It means that biological tissues adapt themselves to changes in the mechanical environment.

Although arteries exhibit viscoelastic characteristics, the assumption of linear-elasticity is made for 


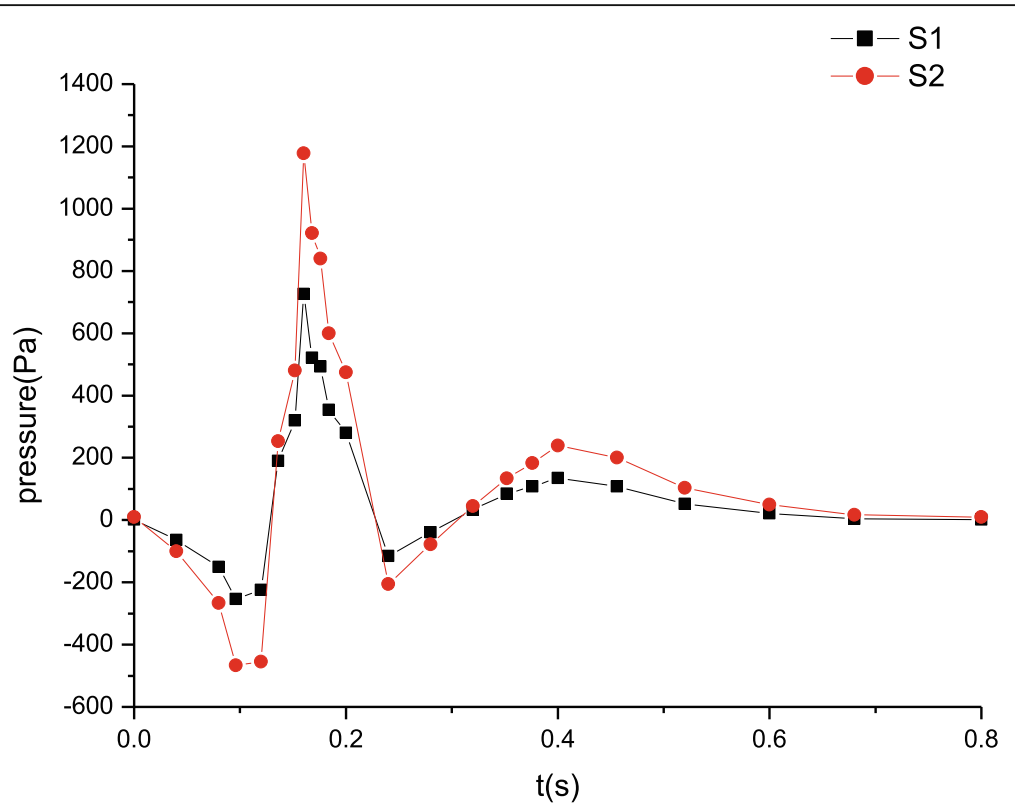

Fig. 9 The maximum pressure distributions in artery zone under rigid wall [7]

computational convenience and it is sufficient in most physiologic and pathophysiologic cases [24]. The most well used arterial wall constitutive equation is based on linear elastic, incompressible and isotropic assumptions, which are widely recognized as an appropriate method for wall mechanics in the physiological range of intraarterial pressures [32]. In fact, these assumptions do not change the displacement profiles of vascular wall. However, the maximum displacement using the viscoelastic model is smaller than the one with the linear elastic model with finite strain. Thus, the maximum wall shear stress is smaller for the viscoelastic model than for the linear elastic models [33]. It should be suggested that the mechanics of nonlinear and anisotropic wall is considerably required for improving the model precision. Therefore, it should be pointed out that this is a methodological paper using an idealised geometry. We will intend to apply this to patient-specific vascular

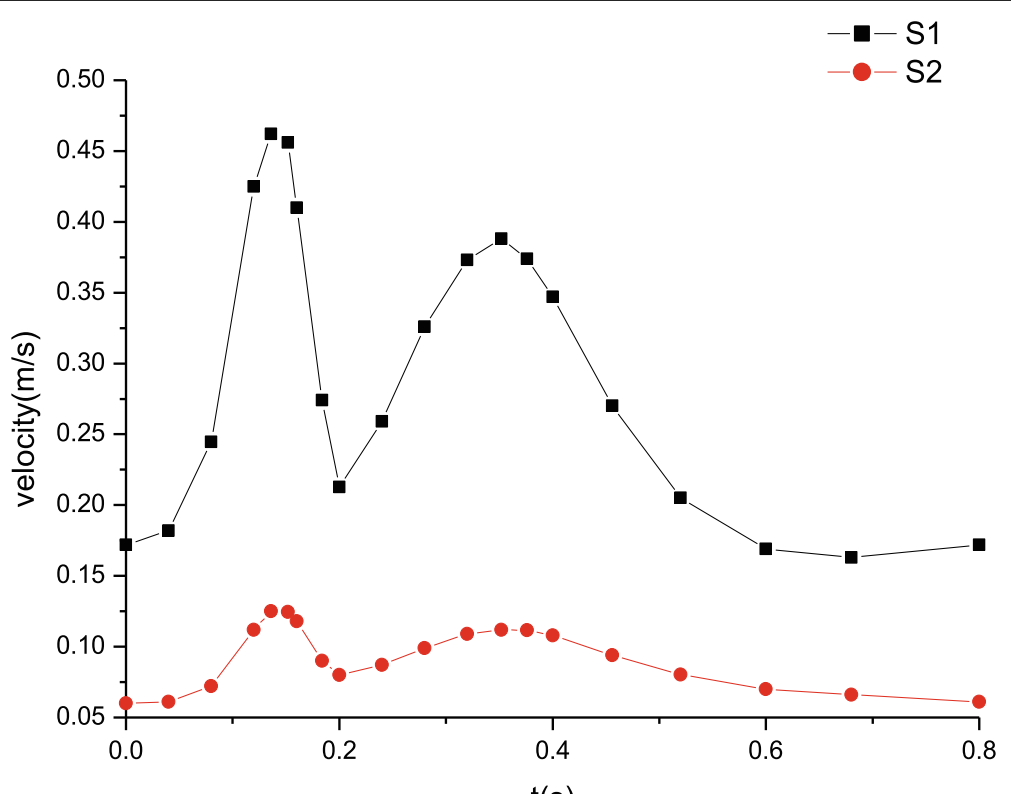

$\mathrm{t}(\mathrm{s})$

Fig. 10 The maximum velocity distributions in artery zone under rigid wall [7] 


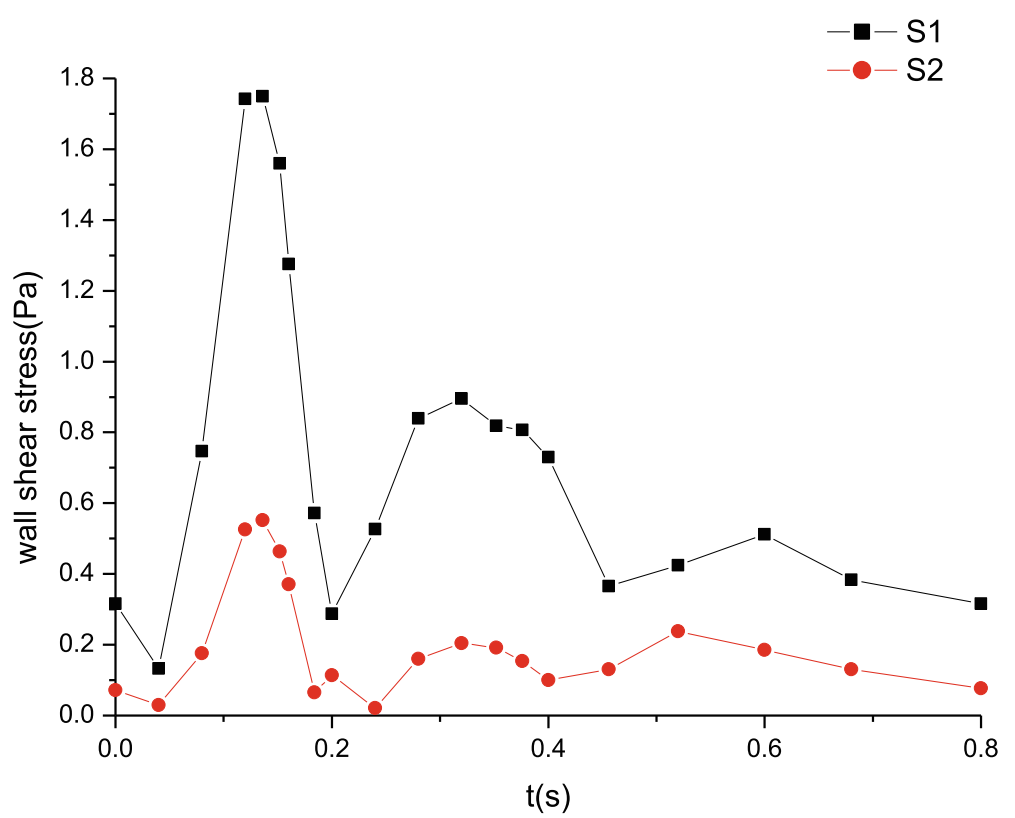

Fig. 11 The maximum wall shear stress distributions in artery zone under rigid wall [7]

geometries and thus provide some comparison with physiological curves for further validating the accuration.

\section{Conclusions}

This investigation provides the valuable study of hemodynamics under physiological and realistic boundary conditions. The effects of wall compliance on flow patterns in hemodynamics modeling based on a seepage outlet boundary condition are detailedly discussed. Under the seepage outlet condition, wall compliance leads to the increase of wall shear stress in contrast to rigid wall, which is the novelty of this work, contrary to the traditional result that wall compliance makes wall shear stress decrease when a constant or time dependent pressure is specified at an outlet. At this point, this work proves that wall compliance positively affects wall shear stress. Certainly, it should be noted that these results are obtained based on an idealised model. The results of real model simulations should be further verified. This methodology in this paper could be used in future work.

\section{Acknowledgments}

Not applicable.

\section{Authors' contributions}

Fan He made crucial initial contributions to the manuscript, especially for medical modelling. Lu Hua and Tingting Guo collected the remaining literature for related approaches and data. All authors contributed substantially to the manuscript as well as critically read and corrected the final version. The authors read and approved the final manuscript.
Funding

This study is supported by National Natural Science Foundation of China (81401492), the Science and Technology Project of Beijing Municipal Commission of Education (KM201510016012). It is also supported by the National Clinical Research Center for Cardiovascular Diseases, Fuwai Hospital, Chinese Academy of Medical Sciences (Grant No. NCRC2020007) and CAMS Innovation Fund for Medical Sciences (2017-I2M-3-003).

Availability of data and materials

The data used to support the findings of this study are included within the article.

Ethics approval and consent to participate

Not applicable.

\section{Consent for publication}

Not applicable.

\section{Competing interests}

The authors declare that they have no competing interests.

Received: 21 July 2020 Accepted: 11 January 2021

Published online: 19 January 2021

References

1. Schachinger V, Britten MB, Zeiher AM. Prognostic impact of coronary vasodilator dysfunction on adverse long-term outcome of coronary heart disease. Circulation. 2000;101:1899-906.

2. Cohn JN, Quyyumi AA, Hollenberg NK, Jamerson KA. Surrogate markers for cardiovascular disease: functional markers. Circulation. 2004;109(IV):31-46.

3. Leung DY, Leung M. Non-invasive/invasive imaging: significance and assessment of coronary microvascular dysfunction. Heart. 2011;97(7):587-95.

4. Debbaut C, Vierendeels J, Casteleyn C, Cornillie P, Loo DV, Simoens P, Hoorebeke LV, Monbaliu D, Segers P. Perfusion characteristics of the human hepatic microcirculation based on three-dimensional reconstructions and computational fluid dynamic analysis. J Biomech Eng. 2012;134(1):011003.

5. Lee J, Smith NP. The multi-scale modelling of coronary blood flow. Ann Biomed Eng. 2012:40(11):2399-413.

6. Soltani M, Chen P. Numerical modeling of interstitial fluid flow coupled with blood flow through a remodeled solid tumor microvascular network. PLoS ONE. 2013;8(6):e67025. 
7. He F, Hua L, Gao LJ. A seepage outlet boundary condition in hemodynamics modeling. Biomed Tech. 2017:62(5:521-7.

8. Melbin PCP, Nesto RW. Scholarly review of geometry and compliance: biomechanical perspectives on vascular injury and healing. ASAIO J. 2002; 48:337-45.

9. van de Vosse FN, de Hart J, van Oijen CHGA, Bessems D, Gunther TWM Segal A, Wolters BJBM, Stijnen JMA, Baaijens FPT. Finite-element-based computational methods for cardiovascular fluid-structure interaction. J Eng Math. 2003;47(3-4):335-68.

10. Di Martino ES, Guadagni G, Fumero A, Ballerini G, Spirito R, Biglioli P, Redaelli A. Fluid-structure interaction within realistic three-dimensional models of the aneurysmatic aorta as a guidance to assess the risk of rupture of the aneurysm. Med Eng Phys. 2001;23:647-55.

11. Valencia A, Solis F. Blood flow dynamics and arterial wall interaction in a saccular aneurysm model of the basilar artery. Comput Struct. 2006; 84:1326-37

12. Borghi A, Wood NB, Mohiaddin RH, Xu XY. Fluid-solid interaction simulation of flow and stress pattern in thoracoabdominal aneurysms: a patientspecific study. J Fluids Structures. 2008;24:270-80.

13. Perktold K, Rappitsch G. Computer simulation of local blood flow and vessel mechanics in a compliant carotid artery bifurcation model. J Biomech. 1995; 28(7):845-56.

14. Tang D, Yang C, Ku DN. A 3-D thin-wall model with fluid-structure interactions for blood flow in carotid arteries with symmetric and asymmetric stenoses. Comput Struct. 1999;72:357-77.

15. Yang $X L$, Liu Y, Yang JM. Fluid-structure interaction in a pulmonary arterial bifurcation. J Biomech. 2007:40:2694-9.

16. Wolters BJBM, Rutten MCM, Schurink GWH, Kose U, de Hart J, van de Vosse FN. A patient-specific computational model of fluid-structure interaction in abdominal aortic aneurysms. Med Eng Phys. 2005;27: 871-83.

17. Bird RB, Armstrong RC, Hassager O. Dynamics of polymer liquids. New York: Wiley; 1987

18. Chen J, Lu XY. Numerical investigation of the non-Newtonian pulsatile blood flow in a bifurcation model with a non-planar branch. J Biomech. 2006;39:818-32.

19. Zhang M, Fan YB. Computational biomechanics of the musculoskeletal system. Boca Raton: CRC Press Inc; 2014

20. Fung YC. Biodynamics: circulation. New York: Springer; 1984.

21. Li MX, Beech-Brandt JJ, John LR, Hoskins PR, Easson WJ. Numerical analysis of pulsatile blood flow and vessel wall mechanics in different degrees of stenoses. J Biomech. 2007:40(16):3715-24.

22. Pedley TJ. The fluid mechanics of large blood vessels. London: Cambridge University Press; 1980.

23. Fung YC. Biomechanics: mechanical properties of living tissues. New York: Springer-Verlag; 1993.

24. Taylor CA, Humphrey JD. Open problems in computational vascular biomechanics: hemodynamics and arterial wall mechanics. Comput Methods Appl Mech Eng. 2009:198:3514-23.

25. Liu $Y$, Lai $Y$, Nagaraj A, Kane B, Hamilton A, Greene R, McPherson DD, Chandran KB. Pulsatile flow simulation in arterial vascular segments with intravascular ultrasound images. Med Eng Phys. 2001; 23:583-95.

26. Moayeri MS, Zendehbudi GR. Effects of elastic property of the wall on flow characteristics through arterial stenoses. J Biomech. 2003;36: 525-35.

27. Maurits NM, Loots GE, Veldman AEP. The influence of vessel wall elasticity and peripheral resistance on the carotid artery flow wave form: a CFD model compared to in vivo ultrasound measurements. J Biomech. 2007:40: 427-36.

28. Friedman MH, Hutchins GM, Bargeron CB, Deters OJ, Mark FF. Correlation of human arterial morphology with hemodynamic measurements in arterial casts. J Biomech Eng. 1981;103:204-7.

29. Ku D, Giddens D, Zarins C, Glagov S. Pulsatile flow and atherosclerosis in the human carotid bifurcation: positive correlation between plaque and low and oscillating shear stress. Arteriosclerosis. 1985;5:293-302.

30. Shojima M, Oshima M, Takagi K, Torii R, Hayakawa M, Katada K, Morita A Kirino T. Magnitude and role of wall shear stress on cerebral aneurysm computational fluid dynamic study of 20 middle cerebral artery aneurysms. Stroke. 2004;35:2500-5.
31. Valencia AA, Guzmán AM, Finol EA, Amon CH. Blood flow dynamics in saccular aneurysm models of the basilar artery. J Biomech Eng. 2006;128: 516-26.

32. Holzapfel GA, Ogden RW. Constitutive modelling of arteries. Proc Royal Soc A. 2010;466:1551-97.

33. Torii R, Oshima M, Kobayashi T, Takagi K, Tezduyar TE. Fluid-structure interaction modeling of a patient-specific cerebral aneurysm: influence of structural modeling. Comput Mech. 2008;43:151-9.

\section{Publisher's Note}

Springer Nature remains neutral with regard to jurisdictional claims in published maps and institutional affiliations.
Ready to submit your research? Choose BMC and benefit from:

- fast, convenient online submission

- thorough peer review by experienced researchers in your field

- rapid publication on acceptance

- support for research data, including large and complex data types

- gold Open Access which fosters wider collaboration and increased citations

- maximum visibility for your research: over $100 \mathrm{M}$ website views per year

At $\mathrm{BMC}$, research is always in progress.

Learn more biomedcentral.com/submissions 